\title{
A Rare Case of Congenital Methemoglobinemia with secondary polycythemia- Case Report and Literature Review
}

\author{
*Ara $\mathrm{T}^{1}$, Haque $\mathrm{QS}^{2}$, Afrose $\mathrm{S}^{3}$
}

\begin{abstract}
Congenital heart diseases are common cause of congenital cyanosis with polycythaemia. Congenital methemoglobinemia is a rare cause of lifelong cyanosis with polycythemia. Congenital methemoglobinemia is caused either by enzyme deficiency or by an abnormal $\mathrm{Hb}(\mathrm{Hb} \mathrm{M})$. Asymptomatic despite presence of severe cyanosis indicates this rare disorder. We are reporting a rare case of polycythemia with cyanosis due to congenital methemoglobinemia. The patient was referred to our centre and attended Hematology OPD (out-patient department) when his routine CBC revealed erythrocytosis. At that time, we found him severely cyanosed especially apparent on lips, tongue, hands and feet. He was diagnosed as a case of congenital methemoglobinemia with 38\% blood methemoglobin level (normal value-0.00-2.00\%). On view of life long persistent cyanosis, without any cardiopulmonary and neurological abnormality, consanguinity of parent's marriage, dark colored blood with high methemoglobin level, a final diagnosis of Type I enzyme deficiency congenital methemoglobinemia was made. He was treated with oral ascorbic acid $250 \mathrm{mg}$ twice daily. At follow up after 6 months his skin color improved and RBC count returned to normal. We are reporting this case of congenital methemoglobinemia for the first time in Bangladesh to emphasize the importance of this rare entity in the differential diagnosis of asymptomatic cyanosis with polycythemia.
\end{abstract}

Key Wards: Secondary Polycythemia, Congenital Methemoglobinemia.

\section{Introduction}

Polycythemia or Erythrocytosis due to high red cell mass is a common reason for referral to a hematologist. Absolute erythrocytosis results from increased red cell mass which includes primary and secondary polycythemia. Primary polycythemia- Polycythaemia Rubra Vera (PRV) is not dependent on hypoxia or increased level of erythropoietin (EPO) hormone which is a malignant myeloproliferative disorder associated with JAK-2 mutation. Secondary Polycythemia may be congenital or acquired. Rare congenital causes include hemoglobin mutations resulting in increased oxygen affinity, EPO receptor mutations, and mutations affecting regulation of EPO production for example, Chuvash polycythemia. Patients with polycythemia having high red blood cell mass usually have plethora or a ruddy complexion. However, if the polycythaemia is secondary to hypoxia, as in venous-to-arterial shunts or compromised lung and

\section{Author's}

1. *Tasneem Ara, Department of Haematology and BMT, Dhaka Medical College, Dhaka, Bangladesh.

2. Qazi Smita Haque, Department of Haematology, Apollo Hospital ltd, Dhaka, Bangladesh.

3. Salma Afrose, Department of Haematology and Transfusion Medicine, Bangladesh Institute of Research and Rehabilitation in Diabetes, Endocrine and Metabolic Disorders (BIRDEM), Dhaka, Bangladesh.

Correspondence: Tasneem Ara, Department of Haematology and BMT, Dhaka Medical College, Dhaka, Bangladesh, e-mail: tasneemara212@gmail.com, contact: +880 15523-14402

20 | Page oxygenation, patients can also appear cyanosed. Congenital heart diseases are common cause of congenital cyanosis with polycythemia. Congenital methemoglobinemia is a rare cause of lifelong cyanosis which may present with polycythemia.

Methemoglobin is produced when ferrous iron of heme moiety in the hemoglobin is oxidized to ferric iron. In normal healthy individuals less than $1 \%$ of hemoglobin is present in the oxidized form (methemoglobin), because erythrocytes contain cytochrome b-5 reductase enzyme. Cytochrome-b5 reductase utilizes NADH formed during glycolysis to reduce methemoglobin back to functional hemoglobin. ${ }^{1}$ Methemoglobinemia may be congenital or acquired. Congenital methemoglobinemia is further categorized into two main types-one due to methemoglobin reductase enzyme deficiency and the other due to an abnormal oxygen affinity hemoglobin termed hemoglobin M. ${ }^{2}$ Most of the case reports belong to the acquired type of methemoglobinemia resulted from exposure to oxidizing drugs or chemicals such as dapsone, nitrates, benzene, phenazopyridine, anti-malarial and sulfonamides etc. ${ }^{3-5}$

Unlike acquired methemoglobinemia, recessively inherited congenital deficiency of reducing enzyme [nicotinamide adenine dinucleotide (NADH) cytochrome b5 reductase] is so rare that only a few cases are documented in the medical literature. As it is a very rare disease and usually 
asymptomatic, patient with congenital methemoglobinemia are frequently clinically missed especially when it occurs in dark skinned people. Here, we report a rare case of congenital methemoglobinemia presented with persistent cyanosis and polycythemia who remained unnoticed till early adulthood.

\section{Case Report}

We are presenting a rare cause of polycythemia with lifelong cyanosis due to congenital methemoglobinemia. Our patient was 18 years old, Bangladeshi Muslim nonsmoker male. His story started three months prior to presentation to our center when he developed episodic spasmodic pain (moderate in intensity) in the upper abdomen and had consultation with a Medicine specialist and investigations were done. Upper GI endoscopy was done but no abnormality was found. However routine CBC revealed Erythrocytosis. CBC revealed high red cell count: $6.7 \times 106 / \mathrm{uL}$ (normal value: 4.5-5.5 $\times$ $10^{6} / \mathrm{uL}$ ). The patient was evaluated in other center for polycythemia and was advised to do bone marrow examination and JAK-2 mutation analysis. Then the patient was referred by his primary physician to our centre and attended our hematology Out-Patient department (OPD) on August 2016 for evaluation of his polycythaemia. At that time, we found him severely cyanosed especially apparent on lips, tongue, hands and feet. On queries his father told that he was born a blue baby and had persistent slate blue coloration of skin since birth. The baby used to have traditional treatment including herbal medicine but no consultation with any physician until he became 3 years old. At that time, he had a cut injury and his parents became worried to see black blood coming from the wound and brought him to a tertiary level hospital. After initial investigations he was declared not to have any major abnormality and as he had no other physical complaints, he did not undergo any further diagnostic evaluation and went home. The discoloration of lips and other parts of the body was persistent and not related to intake of any drug, any particular food, any illness, or any season of the year and did not improve with any particular posture. He also complained of reduced exercise tolerance since his childhood, therefore he used to avoid playing outdoor games. There was no history of developmental delay, palpitation, cough, and breathlessness on lying position, altered mental status, convulsion or unconsciousness. No history of medications intake or exposure to oxidant chemicals were found. There was history of consanguinity of marriage in his parents (1st cousins). He had two siblings; both of them were in good health. None of his parents or any relative had suffered from such type of illness. On examination, there was generalized dusky bluish skin with central and peripheral cyanosis especially apparent on lips, tongue, tip of the fingers and toes. Patient also had congested palpebral conjunctiva. There was no clubbing or edema. Systemic examination revealed no abnormality. $\mathrm{Hb}: 18.2 \mathrm{gm} / \mathrm{dl}$ (normal value: $12-16 \mathrm{gm} / \mathrm{dl}$ ), RBC: 6.47 x 106/uL (normal value: 3.5-6 x106/uL) HCT: $53.8 \%$ (normal value: $37-52 \%$ ) MCV: $85.5 \mathrm{fL}$ (normal value:76-96 fl), $\mathrm{MCH}: 26.3 \mathrm{pg}$ (normal value: 27-32 pg), MCHC: $30.7 \mathrm{~g} / \mathrm{dl}$ (normal value: $30-35 \mathrm{~g} / \mathrm{dl}$ ). In peripheral blood film no atypical cells were detected. Renal and liver function tests, $\mathrm{x}$-ray chest, ECG, Echocardiography, and Ultrasonography of the whole abdomen all were normal. Arterial blood gas analysis showed $\mathrm{pH}:$ 7.33(7.35-7.45), $\mathrm{SaO}_{2}: 96.6 \%$ (95-98), $\mathrm{PCO}_{2}: 39.4 \mathrm{mmHg}((35-45)), \mathrm{HCO}_{3}: 21 \mathrm{mmol} / \mathrm{l}$ (21-28) $\mathrm{TCO}_{2}: 22.2 \mathrm{mmol} / \mathrm{l}$ (22-30), $\mathrm{SaO}_{2}: 96.6 \%$ (95-98\%). $\mathrm{PO}_{2} 86 \mathrm{~mm} \mathrm{Hg}$ (83-100) by pulse oximetry. Striking features were saturation gap between oxygen saturation by pulse oximetry and by arterial blood gas analysis. Arterial blood gas analysis revealed oxygen saturation $\mathrm{SaO}_{2}$ : $96.6 \%$ (95-98\%) whereas in Pulse oximetry revealed oxygen saturation $\mathrm{SpO}_{2}: 86 \%$ $(84-96 \%)$. The patients' clinical picture including cyanosis in absence of any evidence of cardio respiratory distress gave us a clue to the diagnosis. This Saturation gap and normal oxygen saturation in a severely cyanosed patient provided us possible clue to diagnosis. Then an easy bed side test for determining whether the dark blood is due to met- $\mathrm{Hb}$ or deoxy-Hb was done His venous blood was exposed to $100 \%$ oxygen but failed to show color change (Figure:1). Patients' blood also failed to show color change when oxygen was applied. Blood methemoglobin level was measured by spectrophotometry and very high $38 \%$ met $\mathrm{Hb}$ (normal value- $0.00-2.00 \%$ ) was found. $\mathrm{Hb}$ electrophoresis showed normal electrophoretic pattern ( $\mathrm{Hb} \mathrm{A}-\mathrm{Hb}-97.7 \%, \mathrm{Hb} \mathrm{A} 2-2.3 \%$ ), no abnormal band detected. Finally based on very high methemoglobin level diagnosis of congenital methemoglobinemia was established probably due to enzyme deficiency although enzyme level could not be measured due to lack of facility. He responded very well to ascorbic acid administration. At follow up after 6 months his skin color improved and $\mathrm{RBC}$ count returned to normal.

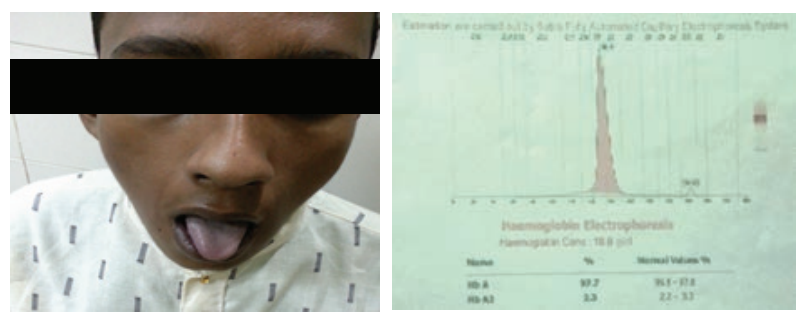

Figure 1: Central Cyanosis Figure 2: Hb Electrophoresis report. 


\section{Discussion}

Congenital methemoglobinemia is a rare clinical disorder characterized by life-long cyanosis, caused by either inherited mutant hemoglobin (Hb-M) or due to methemoglobin Cytochrome b5reductase enzyme gene mutation. ${ }^{6}$

Enzyme deficiency leads to two different types of recessive congenital methemoglobinemia. In type I, cyanosis is the only major symptom and is restricted only to the red blood cells presents as uncomplicated, benign methemoglobinemia even when methemoglobin (met-Hb) levels are as high as $40 \%$ of the total hemoglobin (Hb) value. ${ }^{8}$ In the words of Jaffe and Hultquist, "These patients are really more blue than sick". ${ }^{2}$ As in our patient having very high methemoglobin (38\%) had only vague clinical complaints and remained undiagnosed until 16 years of age.

In type II, affecting all tissues and cyanosis is associated with severe mental retardation and neurological impairment. ${ }^{7}$ As no neurological abnormalities were detected in our patient and presentation was at early adulthood diagnosis of type II enzyme deficiency was excluded.

Compensatory erythrocytosis has been reported in patients with recessive hereditary methemoglobinemia, because methemoglobin alters oxygen affinity of the hemoglobin molecule and induce left shift in the oxyhemoglobin dissociation curve. The presence of iron in the ferric $[\mathrm{Fe} 3+]$ state results in allosteric changes to the molecule that shifts the oxygen-dissociation curve to the left. This shift leads to increased affinity of the ferrous iron for oxygen. ${ }^{8,9}$ The end result of these changes is decreased oxygen delivery leading to tissue hypoxia compensatory erythrocytosis. Our patient also had compensatory erythrocytosis having $18.2 \mathrm{gm} / \mathrm{dl} \mathrm{Hb}$, number of RBCC: 6.47 x 10\%

One study reported a case of methemoglobinemia, presented with polycythemia and misdiagnosed as a case of PRV, who was even treated with Imatinib. ${ }^{10}$ One of the striking features of methemoglobinemia is saturation gap. This occurs when there is a difference between the $\mathrm{PO} 2$ that has been measured by means of pulse oximetry (the lower value) and the $\mathrm{PaO}_{2}$ that has been calculated by means of arterial blood-gas analysis. Typically, this saturation gap is greater than $5 \%$ in cases of methemoglobinemia. ${ }^{11,12,13}$

Persistent Chocolate discoloration of blood in test tube which failed to show change on $100 \%$ oxygen provided us clue to the diagnosis. It was not the deoxygenated blood that was responsible for cyanosis of methemoglobinemia 22 | Page rather abnormal hem pigment met $\mathrm{Hb}$ was responsible for this brownish/slate skin colour. ${ }^{14}$ So, unlike venous blood which contains deoxygenated blood patients met $\mathrm{Hb}$ containing blood remained same. Our patient demonstrated all of the classical features of congenital methemoglobinemia on presentation. Finally, blood methemoglobin measurement confirmed the diagnosis of methemoglobinemia.

Abnormal hemoglobin, such as hemoglobin $\mathrm{M}$ having autosomal dominant inheritance can be detected by electrophoresis, so electrophoresis is a useful tool for the differential diagnosis of congenital methemoglobinemia. ${ }^{15}$ The normal hemoglobin electrophoresis of our patient made the diagnosis of hemoglobin $\mathrm{M}$ unlikely as the cause of the methemoglobinemia ( $\mathrm{Hb}$ A: 97.7\%, $\left.\mathrm{Hb} \mathrm{A}_{2}: 2.7 \%\right)$.

Asymptomatic despite presence of severe cyanosis indicates this rare disorder. Due to rarity of the disease and lack of awareness may lead to under diagnosis of the potentially dangerous disease which poses life threatening condition when exposed to oxidizing agents especially dangerous anesthetic agents. ${ }^{16,17}$

\section{Conclusion}

Acquired methemoglobinemia caused by reducing agent is sometimes seen in routine practice but congenital methemoglobinemia is very rare and only few cases have been documented in the medical journals. We are reporting this case of congenital methemoglobinemia for the first time in Bangladesh. We would like to give emphasis on this rare entity on the differential diagnosis of polycythaemia with cyanosis. Failure to clinical suspicion may lead to false diagnosis and unnecessary investigations. Diagnosis of this rare disorder is based on strong clinical suspicion when cyanosis is present from birth without any cardiac or pulmonary impairment.

\section{References}

1. Skold A, Cosco DL, Klein R. Methemoglobinemia: pathogenesis, diagnosis, and management. South Med J. 2011 Nov 1;104(11):757-761.

2. Jaffe ER. Cytochrome b5 reductase deficiency and enzymopenic hereditary methemoglobinemia. In: Scriver CR, Beaudet AL, Sly WS, et al. editors. The Metabolic and Molecular Basis of Inherited Disease.7th ed. New York: McGraw-Hill; 1995. p. 2267-2280.

3. Pierce JM, Nielsen MS. Acute acquired methaemoglobinaemia after amyl nitrite poisoning. BMJ (Clinical research ed.). 1989 Jun;298(6687):1566 
4. Kern K, Langevin PB, Dunn BM. Methemoglobinemia after topical anesthesia with lidocaine and benzocaine for a difficult intubation. Journal of clinical anesthesia. 2000 Mar $1 ; 12(2): 167-172$.

5. Cohen RJ, Sachs JR, Wicker DJ, Conrad ME. Methemoglobinemia provoked by malarial chemoprophylaxis in Vietnam. New England Journal of Medicine. 1968 Nov 21;279(21):1127-1131.

6. Fermo E, Bianchi P, Vercellati C, Marcello AP, Garatti M, Marangoni O, Barcellini W, Zanella A. Recessive hereditary methemoglobinemia: two novel mutations in the NADH-cytochrome b5 reductase gene. Blood Cells, Molecules, and Diseases. $2008 \mathrm{Jul}$ $1 ; 41(1): 50-55$

7. Hirono H. Lipids of myelin, white matter and gray matter in a case of generalized deficiency of cytochrome b5 reductase in congenital methemoglobinemia with mental retardation. Lipids. 1980 Apr;15(4):272-275.

8. Wright RO, Lewander WJ, Woolf AD. Methemoglobinemia: etiology, pharmacology, and clinical management. Annals of emergency medicine. 1999 Nov 1;34(5):646-656.

9. Curry S. Methemoglobinemia. Ann Emerg Med. 1982 Apr; 11(4):214-221

10. Soliman DS, Yassin M. Congenital methemoglobinemia misdiagnosed as polycythemia vera: Case report and review of literature. Hematology reports. 2018 Mar 2;10(1): 7221.
11. Akhtar J, Johnston BD, Krenzelok EP. Mind the gap. J Emerg Med. 2007 Aug;33(2):131-132.

12. Chan ED, Chan MM, Chan MM. Pulse oximetry: understanding its basic principles facilitates appreciation of its limitations. Respiratory medicine. 2013 Jun 1;107(6):789-799.

13. Rieder HU, Frei FJ, Zbinden AM, Thomson DA. Pulse oximetry in methaemoglobinaemia: failure to detect low oxygen saturation. Anaesthesia. 1989 Apr;44(4):326-327.

14. Haymond S, Cariappa R, Eby CS, Scott MG. Laboratory assessment of oxygenation in methemoglobinemia. Clinical Chemistry. 2005 Feb 1;51(2):434-344.

15. Miller DR. Hemoglobinopathies in children. Massachusetts: PSG Publishing. 1980.

16. Baraka AS, Ayoub CM, Kaddoum RN, Maalouli JM, Chehab IR, Hadi UM. Severe oxyhemoglobin desaturation during induction of anesthesia in a patient with congenital methemoglobinemia. Anesthesiology: The Journal of the American Society of Anesthesiologists. 2001 Nov 1;95(5):1296-1297.

17. Maurtua MA, Emmerling L, Ebrahim Z. Anesthetic management of a patient with congenital methemoglobinemia. J Clin Anesth 2004; 16:455-457. 